\title{
Impact of Envelope Orography on JMA's Hemispheric NWP Forecasts for Winter Circulation
}

\author{
By Toshiki Iwasaki and Akimasa Sumi* \\ Numerical Prediction Division, Japan Meteorological Agency, Tokyo 100, Japan \\ (Manuscript received 4 July 1985, in revised form 10 February 1986)
}

\begin{abstract}
We have investigated some effects of an envelope orography on the forecast fields by a hemispheric spectral model. For that, a series of 29 experiments is conducted for February 1984.

The use of envelope orography improves the daily forecasts. In particular, it remarkably reduces the systematic forecast errors of zonal mean and planetary wave fields. This suggests that the envelopetype enhancement of mountain forcing is very effective in the maintenance of planetary scale stationary fields. In the zonal mean field, the forecast error of latitudinal mass distribution that the surface pressure increases (decreases) in lower (higher) latitudes with increasing forecast period, is reduced. That is, the excessive zonal mean equatorward flow in the lower troposphere at middle latitudes is effectively reduced. This flow change also modifies the predicted zonal mean temperature in the lower troposphere. With regard to the stationary waves, the response of the model atmosphere to the envelope orography varies largely with the latitude. In higher latitudes $(60 \mathrm{~N})$, the improvement of the wave number 3 pattern is most remarkable. Their temporal variation suggests a remote control of the mountain forcings originating from middle latitudes. In middle latitudes $(40 \mathrm{~N})$, a significant difference between the two forecasts with standard and envelope orographies appears around $80 \mathrm{E}$. Its temporal behavior suggests that the difference is directly caused by the difference of mountain forcings around the Himalayas.

Temperature differences between two forecasts occur mainly through the horizontal advection of sensible heat. The forecasts of cold surge events are also modified by the envelope orography.
\end{abstract}

\section{Introduction}

By forecast comparisons Bengtsson and Lange (1981) have clearly indicated that systematic forecast errors (ensemble mean errors for every forecast time) are common to various numerical prediction models and account for one-third of daily forecast errors. The systematic error must originate from errors of quasi-stationary fields in the models. Therefore, we can assume that the mechanisms (e.g., mountain forcings and so on) of their maintenance are commonly insufficient in the models.

Recently, the response of the atmosphere to the various forcings has been investigated as a linear response problem on the spherical domain by many authors (e.g. Gross and Hoskins, 1979;

*Present affiliation: Geophysical Institute, Faculty of Science, Tokyo University, Tokyo 113, Japan.
Hoskins and Karoly, 1981; Simmons et al., 1983). They emphasized the remote response of atmosphere in mid-latitudes to the heating in tropics; any error in the tropics may propagate to the middle and higher latitudes in the model atmosphere and produce systematic errors with planetary scale. In general, the latent heat release by condensation is not accurately parameterized in the models. However, Hollingsworth et al. (1980) showed in their experiment using the two different parameterization schemes for physical processes that both sets of forecasts had similar systematic errors and suggested that there are other forcings to produce them. The mountain forcing is a possible candidate for it. Wallace et al. (1983) clearly showed that the systematic error around the Rockies was related with the wind profile there. They concluded that the mountain forcing was not sufficient in the model 
and proposed a so-called envelope mountain. Using the envelope orography, they showed a reduction of the systematic errors in the ECMWF model. In further studies by ECMWF model, Tibaldi (1985) pointed out that the forecast improvement resulted mainly from the reduction of the excessive tropospheric weaterly in the middle latitudes.

In this paper, we will discuss the effects of envelope orography to the forecast of our 12 layers hemispheric spectral model with truncation of wave number of T42 at JMA (Kanamitsu et al., 1983). The forecast errors will be evaluated by a series of 29 experiments of 3 days forecasts in February, 1984. The systematic error of this model was studied by Sumi and Kanamitsu (1984). Our discussion will be focused on the effects of orographic forcing on the quasi-stationary field, by comparing the systematic errors of the present model with enhanced orography and the operational model with the 'standard' orography.

\section{Brief description of envelope orography}

The envelope orography is constructed in the similar way proposed by Wallace et al. (1983). By using US Navy topographical data set with the resolution of $1 / 6^{\circ}$ latitude longitude grid, the mean height $(\bar{h})$ and standard deviation $(\sigma)$ within the $2.5^{\circ} \times 2.5^{\circ}$ area are calculated and the envelope orography is obtained as $h=\bar{h}+e \sigma$, where $e$ is a scale factor (here, $e=1$ is assumed). Then, the grid point values are expanded in terms of spherical harmonics and smoothed in the same way as in the construction of the standard (routine) orography.

Fig. 1 shows our envelope orography together with the difference between the envelope and standard orographies. Around the Himalayas, the envelope orography is about $1000 \mathrm{~m}$ higher than the standard orography. Around the Alps, the Rockies, northeast Siberia and west Asia, the differences between the two orographies are approximately $600 \mathrm{~m}$. In some regions, the envelope orography becomes a little lower than standard orography. This is mainly due to the wave number truncation and smoothing. Fig. 2 shows zonal wave amplitudes of envelope and standard orographies for each latitude. In the
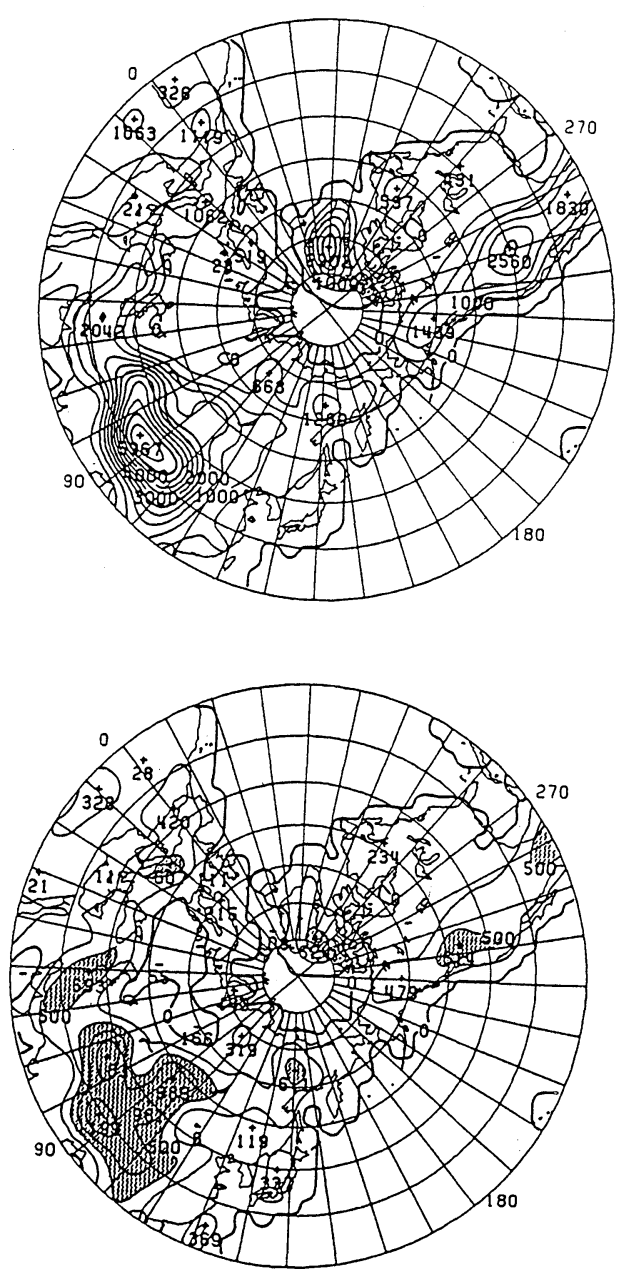

Fig. 1 Patterns of envelope orography and difference between envelope and standard orographies north of $20 \mathrm{~N}$, where the contour intervais of the former and latter are $500 \mathrm{~m}$ and $250 \mathrm{~m}$, respectively. In the latter, the regions with difference larger than $500 \mathrm{~m}$ are shaded.

high latitudes (60N, top), the amplitudes of wave number 1,3 and 4 are enhanced but that of wave number 2 is reduced. In the middle latitudes (40N, middle), both wave number 1 and 2 are largely enhanced. Anyway note that the orography with the planetary scale are mainly enhanced.

\section{Score of forecast}

Fig. 3 shows the time-averaged Root Mean Square Error (RMSE) of $500 \mathrm{mb}$ geopotential height north of $20 \mathrm{~N}$ for the persistence and fore- 

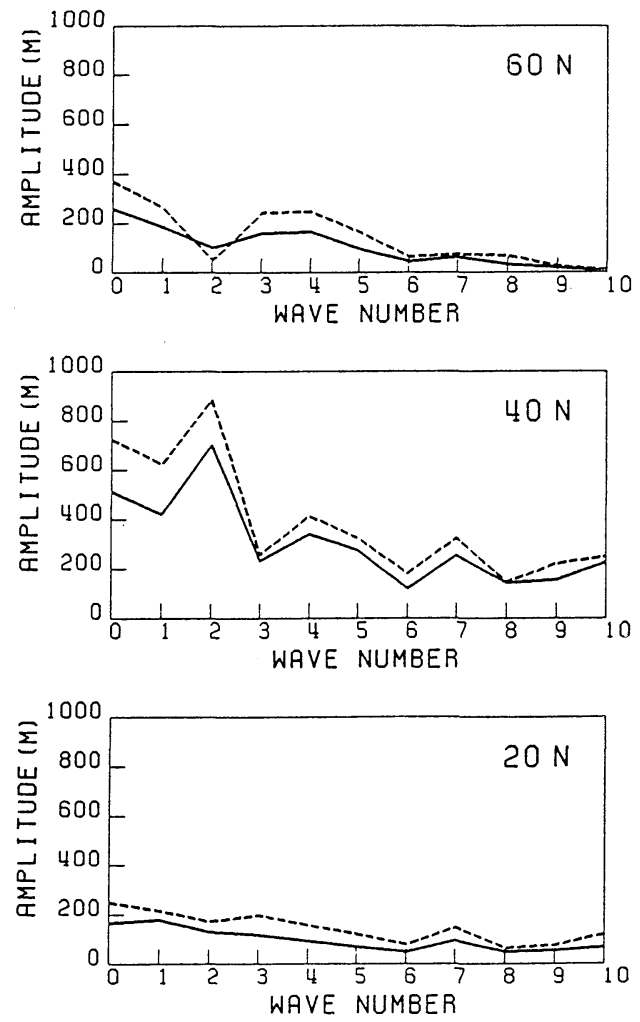

Fig. 2 Wave amplitudes of standard (solid) and envelope (broken) orographies at $60 \mathrm{~N}, 40 \mathrm{~N}$ and 20N. (unit: $\mathrm{m}$ )

casts with standard and envelope orographies. The results of objective analyses operationally conducted at JMA were used as initial conditions and also as references for verification. It is found that the use of envelope orography improves the daily forecasts, especially in the zonal mean and planetary scale wave (zonal wave number 1-4) fields. This result shows larger improvement in comparison with the result by Wallace et al. (1983). In their result, RMSE score showed that the envelope orography improves only zonal mean fields but does not improve total or wave fields until 3 days forecast. This difference of our own and their results may be due to that the mountain forcing in JMA model may be weaker than that of ECMWF model probably because the horizontal resolution of the former is coarser. In fact, Dell'Osso (1984) suggested in his case study with a limited area model that the scale factor for enhancement

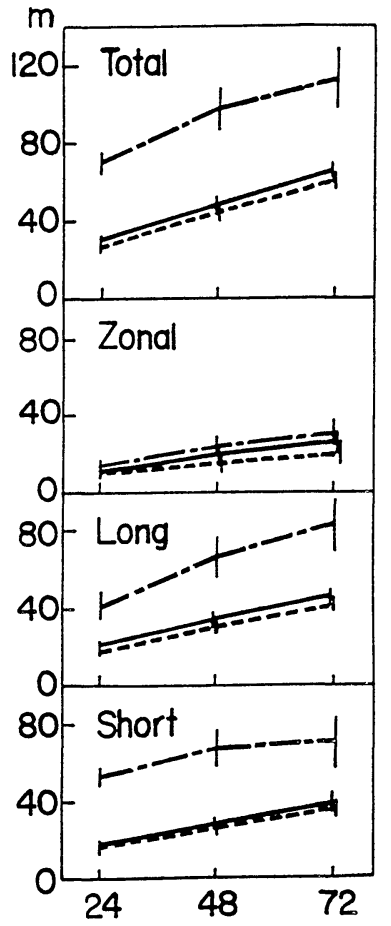

Fig. 329 days means of daily root mean square error of $500 \mathrm{mb}$ geopotential height for total field and zonal mean, long wavelength (zonal wave number 1-4) and short wavelength (520) components, where the horizontal axis indicates forecast hours. Solid, broken and chain lines indicate forecasts with standard and envelope orographies and persistence, respectively, and thin solid lines indicate standard deviations. (unit: $\mathrm{m}$ )

of orography should be increased with decreasing resolution.

Fig. 4 shows the root mean square systematic errors of ensemble mean fields of $500 \mathrm{mb}$ geopotential height forecasts with standard (solid lines) and envelope (broken lines) orography. It is reconfirmed that the systematic error is about half of the time-averaged daily RMSE shown in Fig. 3 and shares a considerable part of daily error. The systematic error is supposed to be produced on the way that the model atmosphere approaches to its own climate. In other words, to improve the model climate is to reduce the systematic error. By using envelope orography, the systematic error is reduced to three-fourths of that of forecasts with standard orography, from a viewpoint of RMSE score. The reductions of sys- 


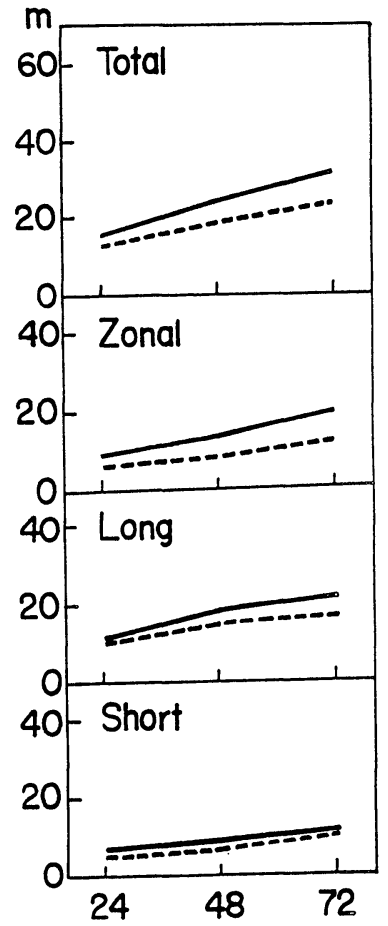

Fig. 4 Root mean square error of $500 \mathrm{mb}$ geopotential height of 29 days ensemble mean fields for forecasts with standard (solid) and envelope (broken) orographies. Others are the same as Fig. 3. (unit: m)

tematic errors in zonal and planetary scale wave fields are more significant than daily errors. Then, we can say that the enhanced envelope orography mainly improves the stationary fields with planetary scale as far as our experiments for February, 1984 are concerned.

\section{Zonal mean field}

Fig. 5 shows the systematic (ensemble mean) forecast errors of zonal means of sea-surface pressure (top), $500 \mathrm{mb}$ geopotential height (middle) and 1000/500 mb thickness (bottom) for 3 days forecasts with standard (solid lines) and envelope orographies (broken lines). One can see that the surface pressure decreases (increases) in the higher (lower) latitudes as the forecast progresses. Such a systematic error of surface pressure was commonly found in many other NWP models and GCM models (Hollingsworth et al., 1980; Derome, 1981; Wallace et al., 1983 and Wallace and Woessener, 1981). It is clearly shown that the error is reduced by using the envelope orography. The difference of the $500 \mathrm{mb}$ geopotential height forecasts between the two models has the same feature as that of the surface pressure. On the other hand, the difference of the $1000 / 500 \mathrm{mb}$ thickness is not so significant. Hence, a large part of the difference of $500 \mathrm{mb}$ height error seems to be that of surface pressure. For example, at $60 \mathrm{~N}$, it is written as follows;

$$
\begin{aligned}
& \Delta \varepsilon\left(Z_{500}\right)=\Delta \varepsilon\left(Z_{500}-Z_{1000}\right)+\Delta \varepsilon\left(Z_{1000}\right) \\
& \sim 18 \mathrm{~m} \sim 5 \mathrm{~m} \sim 13 \mathrm{~m}
\end{aligned}
$$

where the values represent the differences between the two forecasts with the standard and envelope orographies. From this, we can say that the structure of the geopotential height difference is almost barotropic.

In order to confirm the above conclusion, the forecast experiments with 1 layer primitive equation model (divergent barotropic model) with standard and envelope orographies was conducted for February 1984, where the initial fields were given by the objective analyses at the $500 \mathrm{mb}$ level. The response of the barotropic fluid to the envelope orography was similar to the results seen in our multi-layer models. This suggests that the barotropic process plays an important role in the difference of the surface pressure.

Manabe and Terpstra (1974) investigated mountain effects to the atmospheric circulation by comparing the results of GCM with and without mountain. In their result, zonally averaged sea-surface pressure in the GCM with mountain was higher (lower) than that without mountain in higher (lower) latitudes, respectively (Fig. 6). Such sea-surface pressure difference between the two cases with and without mountain in their experiment is similar to the difference of surface pressure in our forecasts with envelope and standard orographies, in spite of difference between a global grid model and a hemispheric spectral model. This suggests that the redistribution of sea-surface pressure is not due to truncation error problem but to a any physical cause.

A possible explanation for the reduction of the surface pressure error is as follows: The enhanced orography may increase mountain 

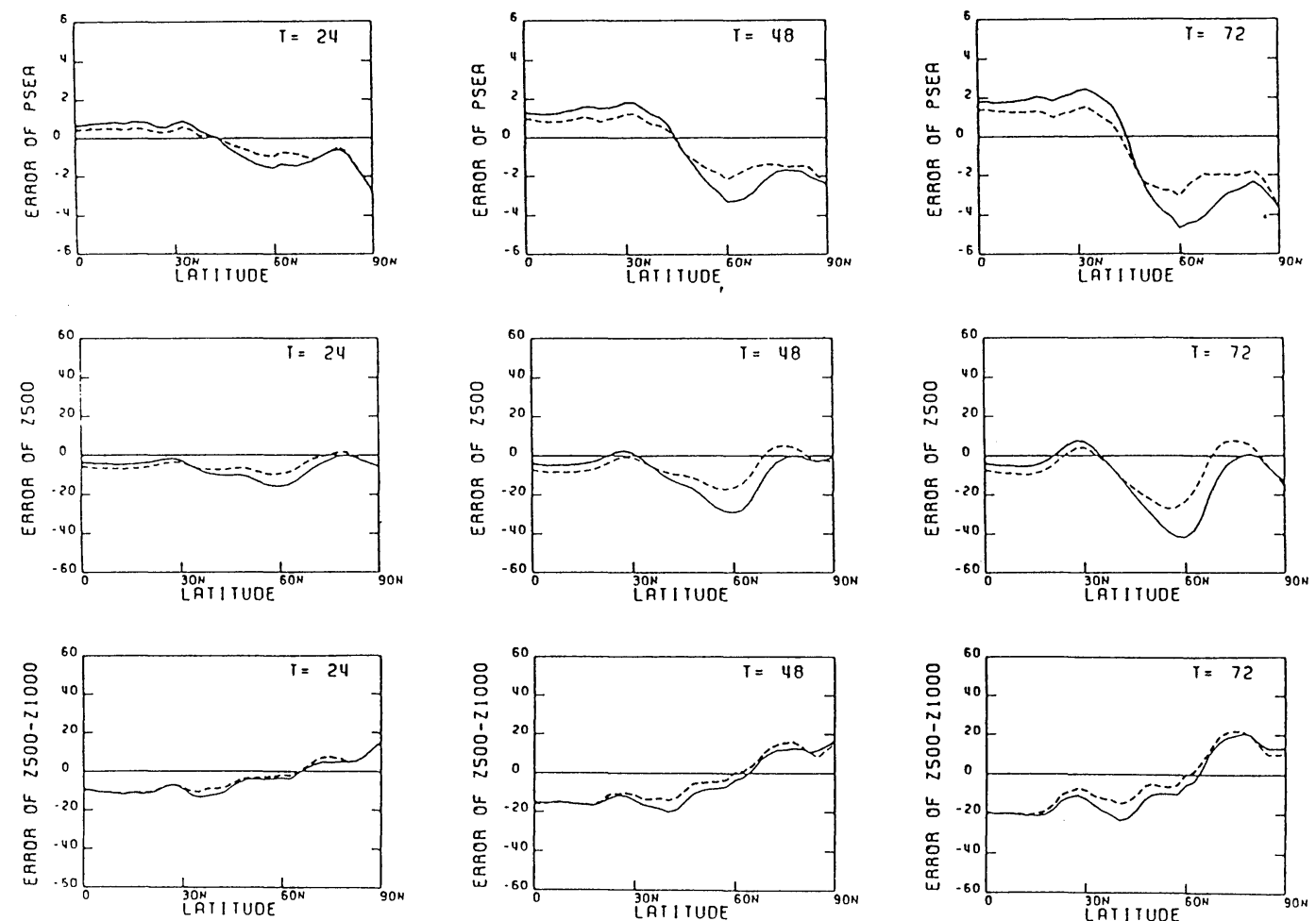

Fig. 5 Systematic errors of zonal means of sea-surface pressure (mb), $500 \mathrm{mb}$ geopotential height $(\mathrm{m})$ and $1000 / 500 \mathrm{mb}$ thickness $(\mathrm{m})$, where solid and broken lines indicate forecasts with standard and envelope orographies, respectively. In the cases of pressure and thickness, the values at the grid points with altitudes in the envelope orography higher than $400 \mathrm{~m}$ are not used to avoid the abiguty originating from extrapolation.

torque and reduce vertically integrated latitudinal zonal westerlies. This reduction means that the pressure gradient decreases through the geo-

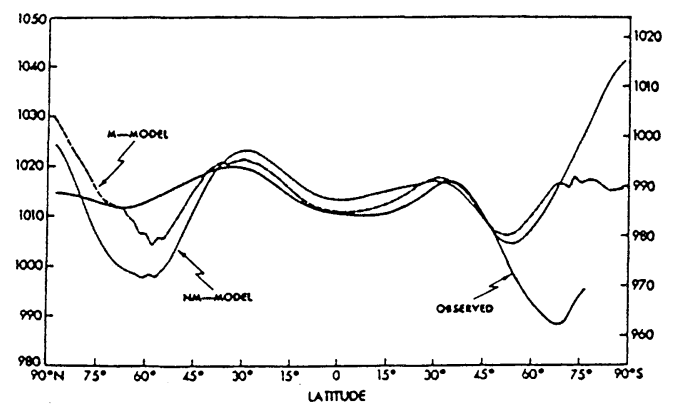

Fig. 6 Latitudinal distribution of zonal mean sea level pressure $(\mathrm{mb})$ - observed, solid line; with mountain ( $M$ model), dashed line; without mountain (NM model), dotted line (after Manabe and Terpstra; 1984). strophic balance as surface pressure decreases (increases) at lower (higher) latitudes.

The mountain torques with standard and envelope orographies at the initial state are shown in Fig. 7 as solid and broken lines, respectively. It shows an increase of the torque in the model with envelope orography in the middle latitudes from $30 \mathrm{~N}$ to $60 \mathrm{~N}$. Also in the ECMWF model, Tibaldi (1985) showed that the use of envelope orography increased the mountain torque. Here, remember that the magnitude of the surface stress term may be also changed by that the model with envelope orography has stronger surface winds even at the same sigma level because of different altitude. This can also work to decrease the zonal momentum. In fact, our day 3 forecasts show that the zonal component of ensemble averages of kinetic energy of forecasts with envelope 


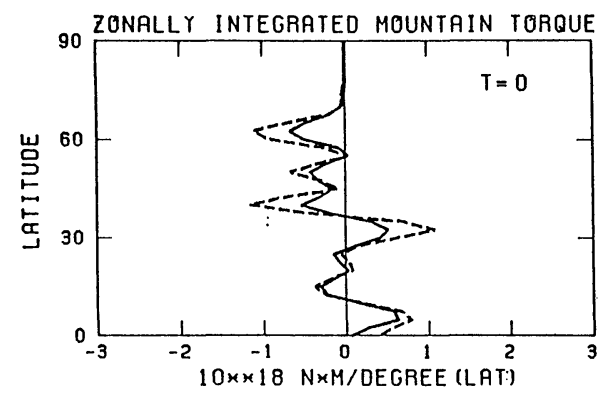

Fig. 7 Zonally integrated mountain torques at the initial time, where solid and broken lines indicate the cases with standard and envelope orographies, respectively. (unit: $10 \mathrm{Nm} /$ degree)

orography is $3 \%$ less than that with standard orography.

Next, the zonal mean of temperature field will be discussed. With regard to the systematic temperature error, both dynamical processes and physical processes such as radiation, sensible and latent heat should be taken into consideration. As shown in Fig. 5, the difference of zonally averaged $1000 / 500 \mathrm{mb}$ thickness between the forecasts with standard and envelope orographies is relatively larger around $40 \mathrm{~N}$, where the wind is strong and the latitudinal gradient of temperature is large. On the other hand, both in higher and lower latitudes, where latitudinal temperature gradients are weaker, the thickness difference is rather small. These facts suggest that the thickness difference is produced by any dynamical processes. If the eddy transport of heat is mainly related to the zonally averaged thickness difference, there should appear both positive and negative biases in it. However, it is positive at all latitudes. Therefore, we can expect that it is produced mainly through the mean meridional advection of sensible heat. Fig. 8 shows the zonal means of temperature forecast error and difference between two models. It is found that the positive thickness difference corresponds to a positive temperature difference in the lower troposphere at middle latitudes. The adiabatic heating due to vertical motion hardly explains such distribution profile of temperature difference. From these considerations, the difference of thermodynamic equation can be approximated as follows;
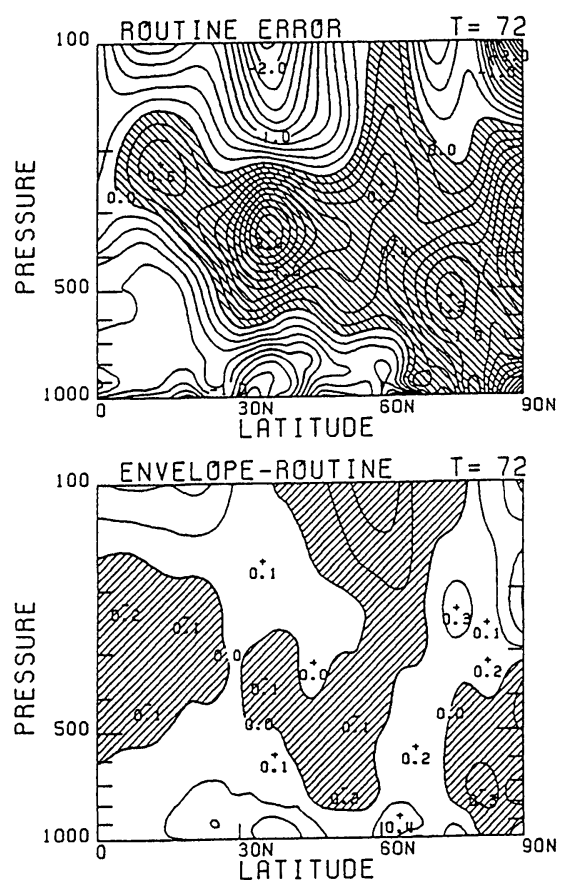

Fig. 8 Zonal means of systematic temperature error (top) and difference (bottom; forecast with envelope orography minus forecast with standard orography) at day 3 forecast, where the contour interval is $0.2 \mathrm{~K}$ and positive error and negative difference are shaded.

$$
\frac{\partial \Delta \bar{T}}{\partial t} \sim-\Delta \bar{v} \cdot \frac{\partial \bar{T}}{\partial y}-\bar{v} \cdot \frac{\partial \Delta \bar{T}}{\partial y^{\prime}}
$$

where bars and deltas denote zonal means and differences between two forecasts, respectively. From an order estimation, it is easily found that the second term of right hand side is negligibly small. In the lower troposphere at middle latitudes, the latitudinal temperature gradient $\left(\frac{\partial \bar{T}}{\partial y}\right)$ is estimated as about $-1 \mathrm{~K} / 100 \mathrm{~km}$, so that the tendency of temperature difference of $\left(\frac{\partial \Delta \bar{T}}{\partial t}\right) \sim 0.5 \mathrm{~K} / 3$ days corresponds to $\Delta \bar{v} \sim 0.2$ $\mathrm{m} / \mathrm{sec}$.

This mass flow change $\Delta \bar{v}$ is related with the above mentioned latitudinal redistribution of surface pressure by using the envelope orography. Integrating the continuity equation of air for region $A$ north of the colatitude of $\varphi$, we can obtain

$$
\frac{\partial \overline{\bar{P}}_{s}}{\partial t} \sim \frac{L}{A} \int_{0}^{\bar{P}_{s}} \Delta \bar{v} d P
$$




$$
\begin{aligned}
& L=2 \pi a \sin \varphi \\
& A=2 \pi a^{2}(1-\cos \varphi)
\end{aligned}
$$

where $\bar{P}_{S}$ and $\overline{\bar{P}}_{S}$ are averaged along the longitudinal belt $L$ and in the area $A$, respectively. Assuming that the latitudinal air mass flow changes $\Delta \bar{v} \sim 0.2 \mathrm{~m} / \mathrm{sec}$ between 1000 and 900 $\mathrm{mb}$ levels at $40 \mathrm{~N}$, the area mean pressure difference is estimated as $1.7 \mathrm{mb} / 3$ days. This seems to be a little larger than the actual pressure difference. Of course, in a strict sense, the eddy effect should be considered in this temperature difference, however major effects can be interpreted as the difference of the mean circulation. The above analyses suggest that the envelope orography changes the latitudinal balance between mass and wind fields mainly through suppression of equatorward wind in the lower troposphere of middle latitudes.

\section{Wave patterns on the spherical domain}

Fig. 9 shows geographical patterns of the systematic error (left) of $500 \mathrm{mb}$ height forecast with standard orography and difference (right) between the two forecasts with standard and envelope orographies at day 1 , day 2 and day 3 forecasts. The shaded regions for each pair of figures well coincide with each other. It indicates that systematic error is reduced. It is also easily found that the difference between two forecasts tends to compensate the systematic error with the planetary scale. The difference of geopoten-

tial height represents the response of the model atmosphere to standard and envelope orographies. In this sense, major source for the difference must exist around the Himalayas and Rockies (see Fig. 1). In the middle latitudes, the positive and negative differences appear in the north and in the downstream sides of those mountains, respectively. It qualitatively agrees with the localized response of westerly to a mountain as discussed by Hoskins and Karoly (1981). They pointed out that the surface ridge and trough form over the mountain and in the downstream side, respectively. From this agreement, it is concluded that the insufficient mountain forcings account for a large part of errors of quasi-stationary waves. Furthermore, the positive difference grows in the north side as the time goes on. This temporal behavior may be related to the propagation of stationary waves. On the other hand, in the lower latitudes, the negative differences in the south of the mountains seem to extend westward. In particular, over the Pacific Ocean, it extends westward as the forecast progresses. This shows that the time evolutions of geopotential height difference are different at latitudes.

Grose et al. (1984) studied the temporal behavior of the atmospheric response to thermal forcing under the realistic zonal flow by using a nonlinear baroclinic model. They showed that the transient modes tended to be baroclinic and zonally propagate, although the stationary modes tended to be barotropic and propagate along a great circle path with NNE direction. In addition, they confirmed that the temporal behavior of the stationary modes including nonlinear effects was qualitatively consistent with linear steady state models as far as the direction of the propagation is concerned (Grose and Hoskins, 1971; Hoskins and Karoly, 1981). If the geopotential field can be interpreted as the linear response, the temporal behavior may be expected in the following; far from the wave source region, the coherence of stationary waves is raised after the wave trains arrive. The time lag can be estimated from its group velocity. On the other hand, near the wave source, the model atmosphere must approach to its own steady state faster.

Analyzing the temporal behavior of the geopotential height changed by the use of envelope orography, we can gain a physical insight into the response of the model atmosphere to these two orographies. The original $500 \mathrm{mb}$ geopotential heights of 3 day forecasts and orographies are shown in Fig. 10. Fig. 11 shows the time evolutions of the systematic error (left) and difference (right) of $500 \mathrm{mb}$ geopotential height. It is clearly shown that the features of time evolution vary greatly with latitude. In the case of $60 \mathrm{~N}$, although the wave patterns of the difference is quite different from that of the original ensemble mean field (Fig. 10), the time evolutions of the error and difference are similar to each other. This similarity suggests that the 

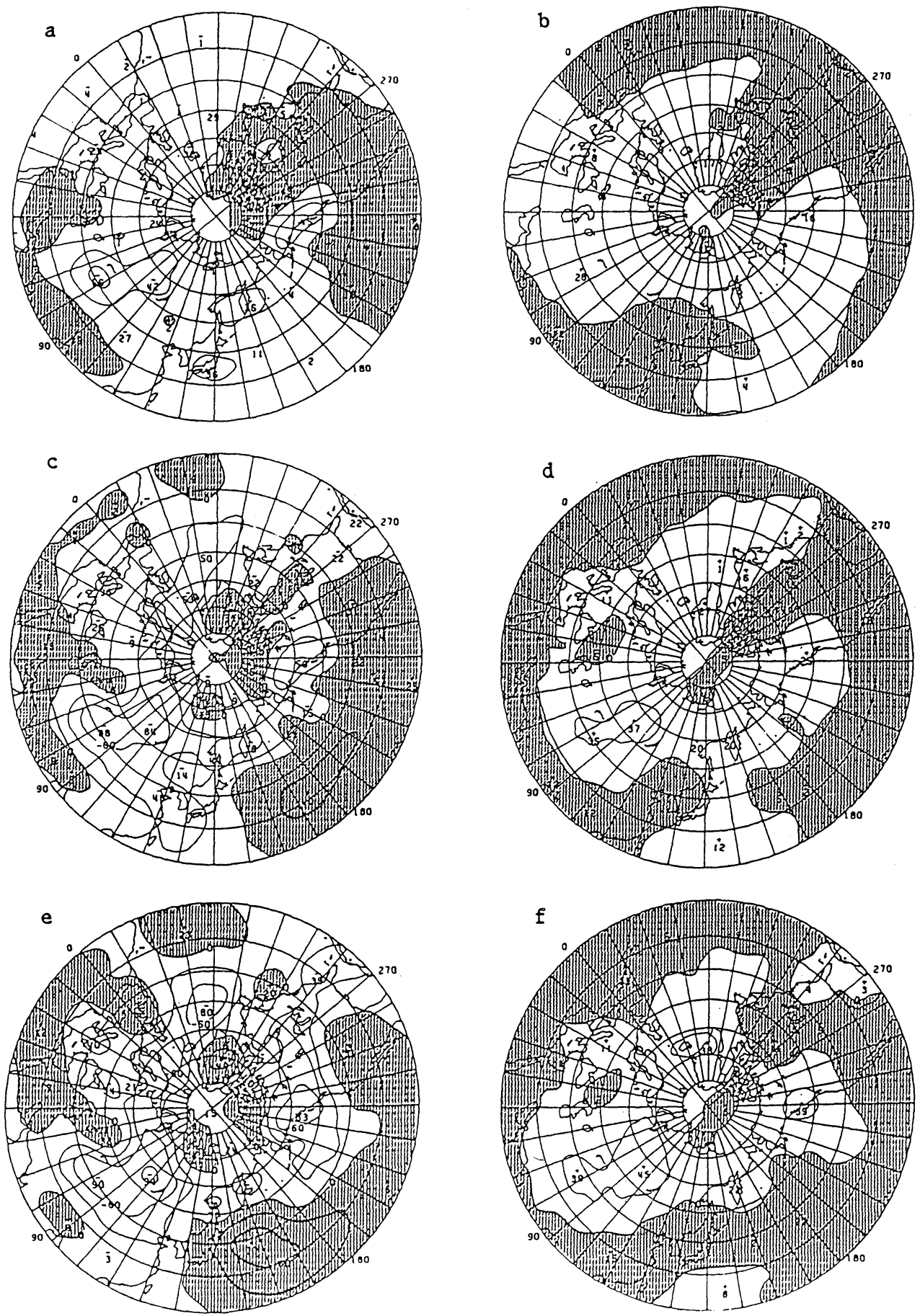

Fig. 9 Systematic $500 \mathrm{mb}$ geopotential height error (a, c, e) and difference (b, d, f; forecast with envelope orography minus forecast with standard orography) north of $20 \mathrm{~N}$, where the contour interval is $30 \mathrm{~m}$. Here, day 1 , day 2 and day 3 forecasts are top (a, b), middle (c, d) and bottom $(e, f)$, respectively. Positive error and negative difference are shaded and the agreement in colors (white or shade) of error and difference means that the difference tends to compensate the error. 

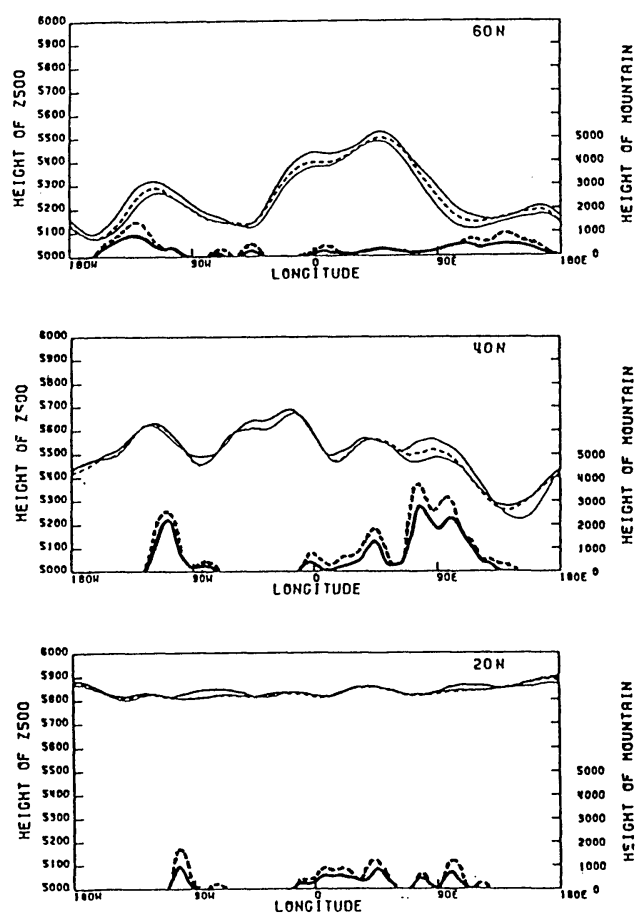

Fig. 10 Longitudinal variances of $500 \mathrm{mb}$ geopotential height of ensemble means of day 3 forecasts at $60 \mathrm{~N}, 40 \mathrm{~N}$ and $20 \mathrm{~N}$, where thin and thick solid lines and broken lines indicate the verification and forecats with standard and envelope orographies. Both orographies are drawn together.

systematic error at this latitude can be mainly attributed to the insufficient mountain forcings. The characteristic feature both in the error and difference is that the zonal wave number 3 is linearly growing with time, at least until day 3 . As shown in Fig. 2, for the envelope orogrpahy at $60 \mathrm{~N}$, the zonal wave number 1,3 and 4 are enhanced, so that some part of the geopotential height difference may be related to the orographic difference at this latitude. However, the linear growth should be noted, because this suggests that these features may be affected by the remote sources as mentioned before. Considering the stationary waves propagating along the great circle path, the forcings in lower latitudes give effects to the wave patterns in this latitude. In particular, a positive difference centered at a point $(57 \mathrm{~N}, 93 \mathrm{E})$, which is easily found in the difference field at day 3 forecast (Fig. 9), is considered to be nearly a linear response to the forcings around the Himalayas (Fig. 1) because the direction and speed of response are well consistent with the stationary wave propagation shown by Grose and Hoskins (1979) and Hoskins and Karoly (1981). Such a wave propagation may also explain the selective enhancement of wave number 3 . They showed that under the realistic winter zonal flow the local stationary wavenumber should be about 3 in the relatively wide area around $60 \mathrm{~N}$ and that the stationary waves which can propagate from lower latitudes to this area were restricted to zonal wavenumber of $1-3$. In the case of point wave source, it takes several days for the wave coherence to extend to global scale. The response to the envelope orography must be due to many sources, so that further studies are needed to confirm the effect of propagation of stationary waves on the short range forecast.

At $40 \mathrm{~N}$, a major feature of the $500 \mathrm{mb}$ height difference is a large positive bias around $80 \mathrm{E}$, which partly compensates a negative bias of the systematic error. This feature rapidly becomes apparent and within 1 day forecast its growth almost saturates. From the above discussion about the temporal behavior based on the linear response, this rapid saturation indicates that wave sources are located much closer to the concerned area than the sources for $60 \mathrm{~N}$. In fact, the positive peak of difference exists near the western edge of the Himalayas, where the difference between these two orographies have a maximum. Such similarity between the error and the difference suggests that the error may be directly caused by insufficient mountain forcing around Himalayas. As seen in other features of the systematic error field, there is short wave-like variance in the western longitudes and a positive bias rising around $160 \mathrm{E}$ for the day 3 forecast, while the difference field has not such variance. The positive error, as shown in Fig. 9, seems to move westward along $30 \mathrm{~N}$ from the eastern Pacific and pile up around $160 \mathrm{E}$ as already been pointed out as a systematic error of this model by Sumi and Kanamitsu (1984). In the difference field, the negative bias moving westward tends to compensate the error a little. However, its effect is small, so the error at day 3 forecast in this region is hardly reduced by 

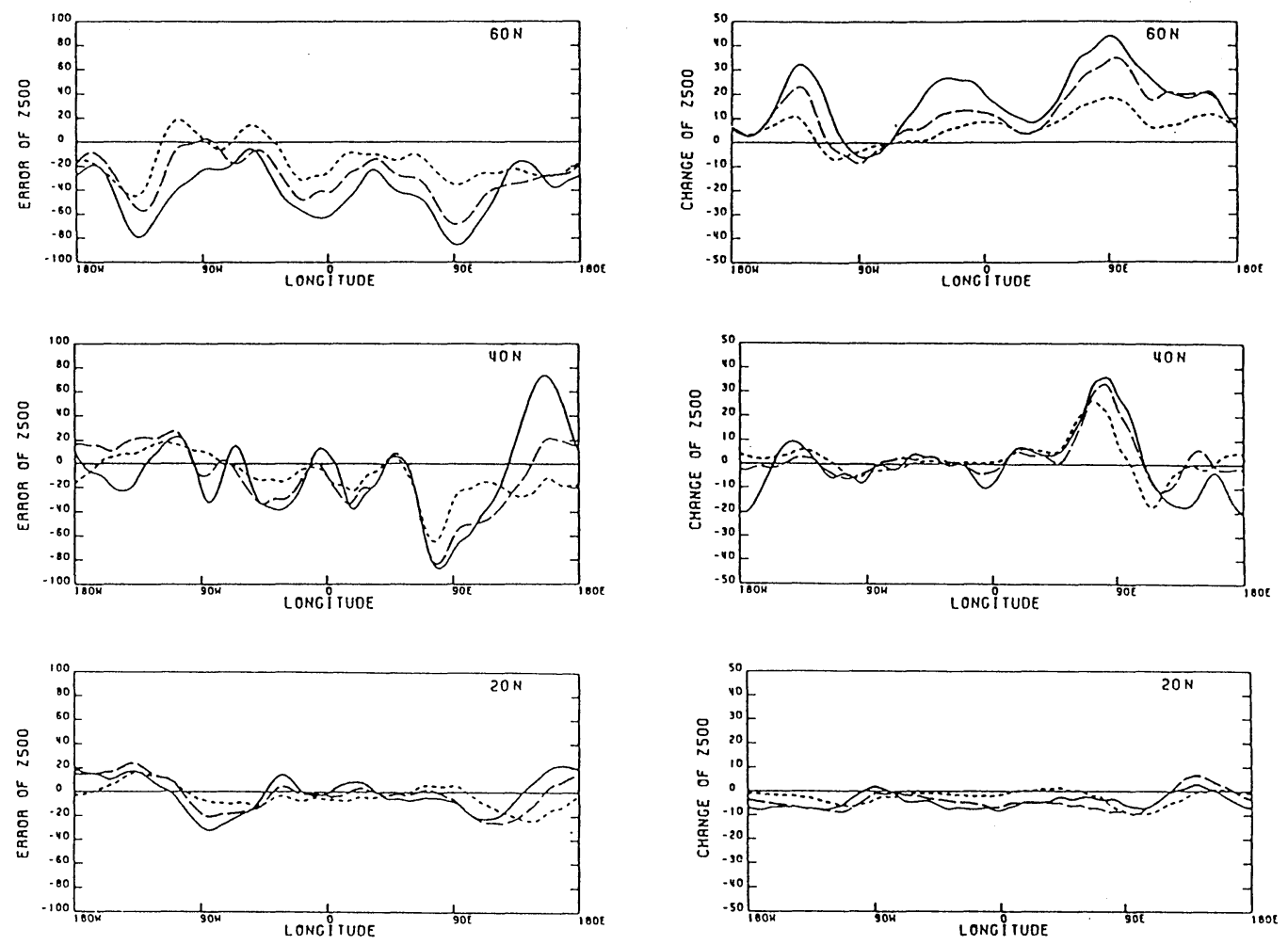

Fig. 11 Time evolutions of systematic error (left) and difference (right; forecast with envelope orography minus forecast with standard orography) of $500 \mathrm{mb}$ geopotential height at $60 \mathrm{~N}, 40 \mathrm{~N}$ and $20 \mathrm{~N}$, where broken lines with short and long intervals and solid lines indicate day 1, day 2 and day 3 forecasts, respectively. (unit: $\mathrm{m}$ )

using envelope orography.

At $20 \mathrm{~N}$, the amplitudes of the systematic error and difference are smaller in comparison with those in middle and high latitudes. The difference is zonally asymmetric against the mountains of Mexico (100W), west Africa (10E) and southeast Asia (100E), with long tails of negative bias on the western sides. These negative biases seem to be hardly enhanced near the mountains after 1 day forecast but extend westward with time. Over the Pacific Ocean, this error may be related to westward propagation of waves along $30 \mathrm{~N}$ as mentioned above and the change tends to compensate the systematic error. The time evolution of the zonally asymmetric features of the error and change are considered to be related to the excitation of transient Rossby waves. The hemispheric spectral model used for this experiment, can not express antisymmetric modes against the equator (Daley et al., 1981). Therefore, more detail discussion about the mountain effects in the lower latitudes is beyond our study.

\section{Temperature field}

The zonal means of temperature difference between forecasts with standard and envelope orographies has already been discussed in section 4. Here, the wave patterns of temperature are discussed. Fig. 12 shows the systematic temperature error and difference of day 3 forecast at $850 \mathrm{mb}$. The temperature difference patterns at $500 \mathrm{mb}$ (the figure is not shown) are almost similar to that at $850 \mathrm{mb}$. Comparing the systematic temperature error to the difference, the variance of the error is much larger than that of the difference. In particular, the positive bias around the pole and negative bias over the Pacific Ocean in the middle latitudes are hardly improved in the error field. This suggests that 

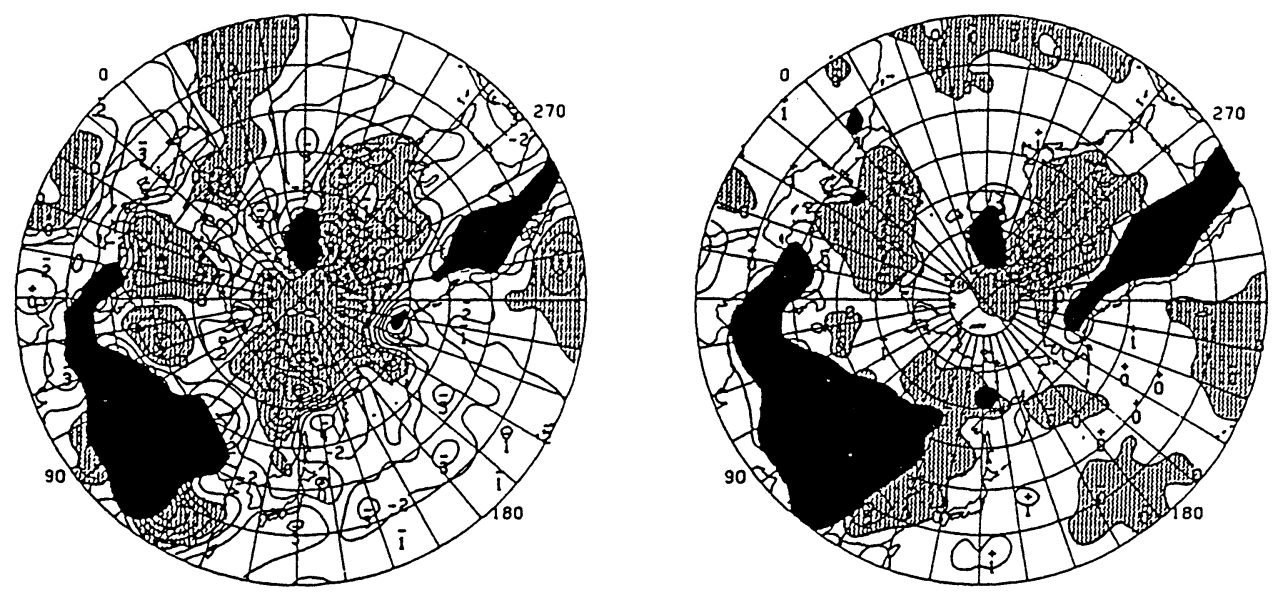

Fig. 12 Systematic error (left) and difference (right; forecast with envelope orography minus forecast with standard orography) of $850 \mathrm{mb}$ temperature with a contour interval of $1 \mathrm{~K}$ in day 3 forecast. Positive error and negative difference are shaded and the regions with standard (envelope) orography higher than $1000 \mathrm{~m}$ are black-colored in the error (difference), respectively.

most of the temperature error does not originate from dynamical processes related to mountain shape.

The wave patterns of temperature difference are expected to be directly influenced by dynamical processes. Roughly speaking, the temperature decreases in the negative region of geopotential height difference field (Fig. 9). Fig. 13 shows the systematic error and difference of northward component of wind (v-component) at $850 \mathrm{mb}$. It should be noted that the negative bias in the temperature difference around mountains almost corresponds to the negative bias in the v-component. Therefore, the response of $850 \mathrm{mb}$ temperature to the difference of orographies may be explained as a difference of horizontal heat advection.

Although the various systematic errors have been analyzed from a view of stationary fields, they could originate from any transient events. Sumi and Kanamitsu (1984) showed that the over-prediction of such events are the major reason for the systematic negative temperature error around east Asia (110E, 30N). Recently, it has been found that the cold surge event in the east of Tibetan Plateau is strongly related with existence of a Kelvin mode due to the side boundary effect of the mountain (e.g., Murakami and Nakamura, 1983; Sumi, 1985;
Nakamura and Doutani, 1985). Therefore, we can say that the cold surge would be sensitive to the mountain height. In this experiment, both systematic errors of temperature and vcomponent are positive around the point of $(110 \mathrm{E}, 30 \mathrm{~N})$. The possible cause for the positive error is that in this February the cold surge is not strong enough to dominate monthly mean error. However, the temperature difference between forecasts with standard and envelope orographies is negative along the mountain in the east of Tibetan Plateau. Note that this difference is trapped along the side boundary of the mountain and corresponds to the negative bias in the difference of v-component. In order to study the effects of the surge events in detail, time sequence of temperature $(850 \mathrm{mb})$ at this point $(110 \mathrm{E}, 30 \mathrm{~N})$ for day 1 , day 2 and day 3 forecasts are shown in Fig. 14, where thin and thick solid lines and broken lines indicate the verifications and forecasts with standard and envelope orographies, respectively. At day 1 forecast, negative temperature errors appear when temperature is low. This is consistent with the overprediction of cold surge events shown by Sumi and Kanamitsu (1984). In addition, the minimum dips are enhanced by using envelope orography. It is evident that the surge events are related with the side boundary effect. At day 

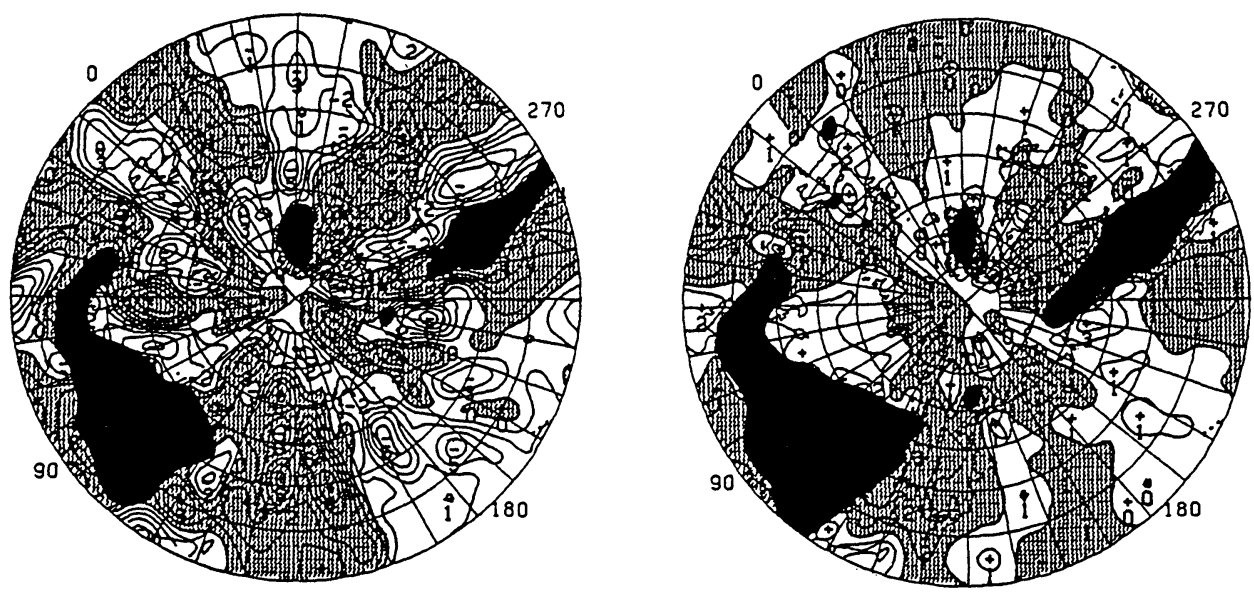

Fig. 13 Same as Fig. 12, except for northward component of $850 \mathrm{mb}$ wind.
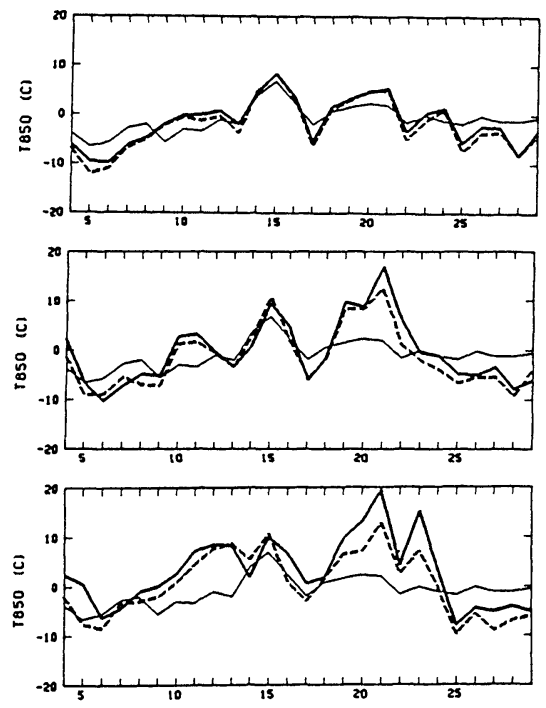

Fig. 14 Time sequences of temperature at the point $(110 \mathrm{E}, 30 \mathrm{~N}, 850 \mathrm{mb})$ for day 1 (top). day 2 (middle) and day 3 (bottom) forecasts, where thin and thick solid lines and broken lines indicate the verifications and forecasts with standard and envelope orographies, respectively. Horizonal axis indicates the verification date.

3 forecast, it is hard to say that the dips are enhanced by using envelope orography. The minimum dips disappear and the temperature forecast errors change to positive. Then, it may be difficult to make any successful day 3 forecasts for surge events, because the large scale fields to excite them can not be well forecasted.

\section{Conclusion}

By using envelope orography, the systematic error in JMA's NWP forecast is remarkably reduced, especially in zonal and planetary wave components. In the zonal mean, the major error is the distribution of air mass such that the surface pressure increases at lower latitudes and decreases at higher latitudes. Such error is suppressed by using envelope orography. The reduction of westerly by enhanced mountain torque changes the latitudinal mass distribution through the geostrophic balance in the model atmosphere. By analyzing the zonal mean of the temperature difference between two forecasts, we can say that when the redistribution of air mass is achieved, excessive equatorward wind in the lower troposphere is mainly suppressed.

Wave patterns of systematic geopotential height error and difference between two forecasts vary strongly with latitude. At $60 \mathrm{~N}$, both error and difference have wave number 3 patterns similar to each other. These patterns almost linearly grow with time at least within 3 days. The results indicate that the error at this latitude is caused mainly from insufficient mountain forcings and affected by propagation of quasi-stationary waves from lower latitudes. At $40 \mathrm{~N}$, a significant positive difference appears around $80 \mathrm{E}$, which compensates about half of negative bias of the systematic error. Both the error and difference rapidly grow and then they soon saturate. It indicates that the differ- 
ence in the mountain forcing around Himalayas directly controls these structures there.

The temperature difference between two forecasts with standard and envelope orographies occurs mainly through dynamical processes, especially, horizontal heat advection. Its large scale feature is almost consistent with quasi-stationary flow field. Also, the envelope orography affects a transient event, namely, cold surge. As far as daily day 1 forecasts are concerned, the surge events are enhanced.

As a whole, the variance and bias of systematic temperature errors of the operational forecasts are much larger than those of temperature difference between the two forecasts. This means that most of the systematic temperature errors of operational forecats do not result from any shortcoming of orographic forcings, and also that the impact of the envelope orography on the systematic error is rather barotropic.

Our experiments indicate that the orographic forcings in the JMA's operational model are weaker than those in the real atmosphere. The $500 \mathrm{mb}$ height difference between forecasts with standard and envelope orographies compensates only about half of the systematic error in the regions where these have good correspondences with each other. Therefore, the orographic forcings are still weaker and we may expect that the larger enhancement of orography would result in further improvement. However, the physical basis of the envelope orography is not well established. One can say that the unsettled choice of multipling factor directly reflects the ambiguity of physical basis of this parameterization. Alternative way to represent the effect of the sub-grid scale orography is to modify the surface drag and gravity wave drag. Further researches should be necessary for such subgrid scale forcings.

\section{Acknowledgement}

The authors wish to express their sincere thanks to Drs. K. Ninomiya, M. Kikuchi, M. Kanamitsu and other staff members of Numerical Prediction Division of Japan Meteorological Agency for useful discussions and constructive comments.

\section{References}

Bengtsson, L. and A. Lange, 1981: Results of the WMO/ CAS numerical weather prediction data study and intercomparison project for forecasts for the northern hemisphere in 1979-1980, PWPR report No. 1.

Daley, R., J. Tribbia and D. L. Williamson, 1981: The existence of large-scale free Rossby waves in numerical weather prediction. Mon. Wea. Rev., 109, $1836-1861$.

Derome, J., 1981: On the averaged errors of an ensemble of forecasts. Atmos-Ocean, 19, 103-127.

Grose, W. L., W. T. Blackshear and R. E. Turner, 1984: The response of a non-linear, time-dependent, baroclinic model of the atmosphere to tropical thermal forcing. Quart. J.R. Met. Soc., 110, 981-1002.

and B. J. Hoskins, 1979: On the influence of orography on large-scale atmospheric flow. $J$. Atmos. Sci., 36, 223-234.

Hollingsworth, A., K. Arpe, M. Tiedtke, M. Capaldo and H. Savijärvi, 1980: The performance of a medium-range forecast model in winter-impact of physical parameterizations. Mon. Wea. Rev., 108, 1736-1773.

Hoskins, B. J. and D. J. Karoly, 1981: The steady linear response of a spherical atmosphere to thermal and orographic forcing. J. Atmos. Sci., 38, 1179-1196.

Kanamitsu, M., K. Tada, T. Kudo, N. Sato and S. Isa, 1983: Description of the JMA operational spectral model. J. Met. Soc. Japan, 61, 812-828.

Dell'Osso, L., 1984: High-resolution experiments with the ECMWF model: A case study. Mon. Wea. Rev., 112, 1853-1883.

Manabe, S. and T. B. Terpstra, 1974: The effects of mountains on the general circulation of the atmosphere as identified by numerical experiments. $J$. Atmos. Sci., 31, 3-42.

Murakami, T. and H. Nakamura, 1983: Orographic effects on cold surge and lee-cyclogenesis as revealed by a numerical experiment Part 2: Transient aspects. J. Met. Soc. Japan, 61, 547-567.

Nakamura, H. and T. Doutani, 1985: A numerical study on the coastal Kelvin wave features about the cold surges around the Tibetan Plateau. J. Met. Soc. Japan, 63, 547-563.

Simmons, A. J., J. M. Wallace and G. W. Branstator, 1983: Barotropic wave propagation and instability, and atmospheric teleconnection patterns. J. Atmos. Sci., 40, 1363-1392.

Sumi, A., 1985: A study on cold surges around the Tibetan Plateau by using the numerical models. J. Met. Soc. Japan, 63, 377-396.

and M. Kanamitsu, 1984: A study of systematic errors in a numerical weather prediction model, Part 1: General aspects of the systematic errors and their relation with the transient eddies. J. Met. Soc. Japan, 62, 234-251.

Tibaldi, S., 1985: Envelope orography and maintenance of quasi-stationary waves in the ECMWF model. Workshop on Global Scale Anomalous Circulation in the Atmosphere and Blocking, IBM Italia, Rome, 
2371, August 1984.

Wallace, J. M., T. Stefano and A. J. Simmons, 1983: Reduction of systematic forecast errors in ECMWF model through the introduction of an envelope orography. Quart. J.R. Met. Soc., 109, 683-717. and J. K. Woessner, 1981: An analysis of forecast error in the NMC hemispheric primitive equation model. Mon. Wea. Rev., 109, 2444-2449.

\section{冬期循環の予報（JMA, 北半球モデル）に対する Envelope Orography のインパクト}

\section{岩崎 俊樹・住 明正 $*$}

\section{気象庁・数值予報課}

北半球モデルの予報に対する Envelope Orography の効果を調べるために，1984年 2 月について29 例の予報実験を行った。

Envelope Orography の導入は日々の予報を改善する。特に, 帯状平均や惑星波等の系統的誤差を著 しく減少させる。これは Envelope Orography がプラネタリースケールの定常場を維持するのにた いへん有効であることを示唆している。带状平均場では，低緯度で増大し，高緯度で減少するという質 量配分の誤差が減少する。この場合, 中緯度の下部対流圈における過度の赤道に向う流れが主に抑之ら れている。この流れの変化は, 下部対流圏の気温予想（带状平均）にも影響を与える。定在波に関して は, モデル大気の Envelope Orography に対する応答は緯度により異っている。60度付近の高緯度で は, 波数 3 の改善が顕著である。その時間的な振舞は中緯度の forcing に対する遠隔的な応答を示唆し ている。中緯度 $(40 \mathrm{~N})$ では, $80 \mathrm{E}$ 付近に顕著な効果が現れる。その時間的な振舞は七マラヤ付近の focing の差に直接誘起されたことを示唆している。

$2 つ の$ 予報の気温の相違は主に熱の水平移流に基づいている。またコールドサージの予報も Envelope Orographyにより変更を受ける。

* 現所属：東京大学理学部 